Aglaja Przyborski

Bildkommunikation 



\section{Aglaja Przyborski}

\section{Bildkommunikation}

Qualitative Bild- und Medienforschung 


\section{Zum Coverbild}

Das Coverbild bringt das Anliegen des Buches, die wechselseitige Konstitution von Medien und Altag im Rahmen von Bildkommunikation zu untersuchen, auf den Punkt: In kommerziellen Bildern findet oft insofern Bildkommunikation statt, als sie gesellschaftliche Imaginationen, Identitätsnormen und Rollenvorstellungen artikulieren. Doch erst Produkte konkreter Alltagspraxen eröffnen den Weg zur kontrollierten empirischen Analyse dieser Bildkommunikation, erst in ihnen wird die Relevanzentfaltung öffentlicher Bilder für bestimmte soziale Felder sichtbar - in ihrer bildspezifischen Form, wie in jener auf dem Cover, in der Öffentliches und Privates nahezu verschmelzen. Die Analyse des Bildes beleuchtet bestimmte Facetten aus dem Leben der beiden Männer sehr nah. Diese Facetten werden für die komparative Analyse stark abstrahiert. All dies kann einer je individuellen Persönlichkeit nicht gerecht werden, nicht zuletzt deshalb werden die Bildschöpfer nicht namentlich genannt, was ihrem eigenen Wunsch entspricht. Den beiden Männern, die in der vorliegenden Publikation als Gruppe „Schaum“ bezeichnet werden, soll an dieser Stelle Dank ausgesprochen werden. Sie haben ihr Bild für die Analysen im Buch und für das Cover zur Verfügung gestellt.

ISBN 978-3-11-050169-8

e-ISBN (PDF) 978-3-11-050170-4

e-ISBN (EPUB) 978-3-11-049884-4

\section{Library of Congress Cataloging-in-Publication Data}

A CIP catalog record for this book has been applied for at the Library of Congress.

\section{Bibliografische Information der Deutschen Nationalbibliothek}

Die Deutsche Nationalbibliothek verzeichnet diese Publikation in der Deutschen Nationalbibliografie; detaillierte bibliografische Daten sind im Internet über http://dnb.dnb.de abrufbar.

(C) 2018 Walter de Gruyter GmbH, Berlin/Boston

Einbandabbildung: Schaum, Wien

Satz: Meta Systems Publishing \& Printservices GmbH, Wustermark

Druck und Bindung: CPI books GmbH, Leck

@ Gedruckt auf säurefreiem Papier

Printed in Germany

www.degruyter.com 